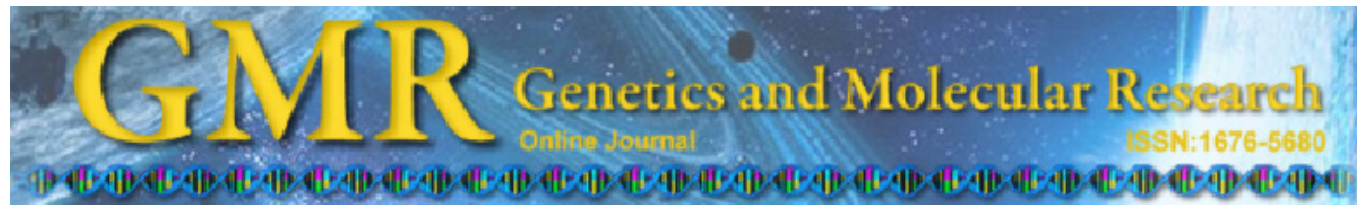

\title{
Effect of $I L-18$ gene promoter polymorphisms on prostate cancer occurrence and prognosis in Han Chinese population
}

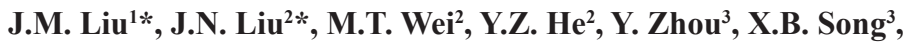 \\ B.W. Ying ${ }^{3}$ and J. Huang ${ }^{2}$ \\ ${ }^{1}$ Department of Urology Surgery, West China School of Medicine, \\ West China Hospital, Sichuan University, Sichuan Province, P.R. China \\ ${ }^{2}$ West China School of Medicine, West China Hospital, Sichuan University, \\ Sichuan Province, P.R. China \\ ${ }^{3}$ Department of Laboratory Medicine, West China School of Medicine, \\ West China Hospital, Sichuan University, Sichuan Province, P.R. China \\ *These authors contributed equally to this study. \\ Corresponding author: J. Huang \\ E-mail: michael.huangjin@gmail.com
}

Genet. Mol. Res. 12 (1): 820-829 (2013)

Received January 31, 2012

Accepted December 15, 2012

Published March 15, 2013

DOI http://dx.doi.org/10.4238/2013.March.15.2

\begin{abstract}
Interleukin-18 (IL-18) has been implicated in a wide variety of cellular functions that affect the biological response to tumors. However, there is insufficient evidence to prove that $I L-18$ gene variants are associated with risk of prostate cancer. We examined a possible association between two promoter polymorphisms, $-137 \mathrm{G} / \mathrm{C}(\mathrm{rs} 187238)$ and $-607 \mathrm{C} / \mathrm{A}(\mathrm{rs} 1946518)$, in the $I L-18$ gene and prostate cancer occurrence and prognosis in Han Chinese. We used a high-resolution melting method to genotype these two polymorphisms in 375 Chinese Han patients with prostate cancer and in 400 age-matched healthy controls. A hundred and eighty-one prostate cancer patients who had been receiving androgen deprivation therapy, including operational and medical castration, were enrolled
\end{abstract}


to follow-up in this study. Carriers of the GG genotype of the $-137 \mathrm{G} /$ C polymorphism had a 2.165-times higher risk of prostate cancer progression than carriers of $\mathrm{GC}[95 \%$ confidence interval $(\mathrm{CI})=$ 1.270-3.687]. Patients with the GG genotype at clinical stages III and IV also had significantly lower rates of progression-free survival (relative risk $=2.174,95 \% \mathrm{CI}=1.211-3.906)$. However, we found no significant association of genotype or allele distributions of these two polymorphisms with occurrence of prostate cancer. We conclude that there is evidence that the $I L-18$ gene promoter polymorphism $-137 \mathrm{G} /$ $\mathrm{C}$ influences the prognosis of prostate cancer patients in androgen deprivation therapy, although neither of the two SNPs contributes to prostate cancer development.

Key words: $I L-18$; Prostate cancer; Polymorphism

\section{INTRODUCTION}

Interleukin-18 (IL-18), an 18-kDa cytokine, is generally referred to as a member of the IL-1 family. Evidence has shown that IL-18 has both anticancer and pro-cancer effects. From one aspect, the expression and secretion of IL-18 is a critical event against oncogenesis. IL-18 has pleiotropic efficacy in activating natural killer cell cytotoxic effect and enhancing Th1 immune response mainly by stimulating the expression of interferon- $\gamma$ and tumor necrosis factor- $\alpha$, therefore resulting in the elimination of tumor cells in vivo (Gillies et al., 1993; Okamura et al., 1995; Dinarello, 1999; Kalina et al., 2000; Marshall et al., 2006). Further evidence was provided by two animal studies reporting that the transfection of the $I L-18$ gene into tumor cells enhanced both specific and nonspecific antitumor immune responses (Han et al., 2004; Xia et al., 2004). On the other hand, recent studies have suggested the pro-cancer effect of IL-18. Higher expression levels of IL-18 have been detected in various cancer cells, such as those in gastric cancer (Ye et al., 2007) and breast cancer (Eissa et al., 2005). Further analysis has shown that IL-18 promotes the expression of vascular endothelial growth factor and degradation of the extracellular matrix to accelerate the process of cancer angiogenesis and migration (Alexandrakis et al., 2004; Jung et al., 2006; Cho et al., 2006; Kim et al., 2007). The data obtained recently also indicated that IL-18 interacts with phosphorylation ERK1/2 (Amin et al., 2007), p38 MAPK, and endogenous oxygen species (reactive oxygen intermediate)signaling pathways (Jung et al., 2006) to induce the apoptosis of immune cells in the tumor immune escape (Yoon et al., 2004).

A possible association between IL-18 and prostate cancer was identified recently. It was reported that by acting as an autocrine or paracrine factor, IL-18 could be produced and secreted by prostate cancer cells in response to interferon (Lebel-Binay et al., 2003). Tse et al. (2011) used murine animal models of prostate cancer to investigate this mechanism and found that local expression of IL-18 in prostate cancer tissue might inhibit the development of this tumor through innate and adaptive immune pathways. Besides this, IL-18BP is a specific inhibitor of IL-18, and its significantly up-regulated expression in the prostatic fluid of cancer status provides indirect proof of the anti-tumor role of IL-18 (Fujita et al., 2008, 2011). IL-18 expression in prostate cancer is also related to tumor outcome such as pathologic stage 
(Lebel-Binay et al., 2003) and the transition from androgen-responsive to hormone-refractory prostate cancer (Desai et al., 2004).

The $I L-18$ gene is located on chromosome 11q22.2-q22.3. Recently, genetic polymorphism loci of $I L-18$ have been confirmed to be associated with many cancers, including ovarian cancer (Bushley et al., 2004) and nasopharyngeal carcinoma (Pratesi et al., 2006). In this study, we investigated the role of $I L-18$ gene promoter polymorphisms $-137 \mathrm{G} / \mathrm{C}$ (rs187238) and $-607 \mathrm{C} / \mathrm{A}$ (rs 1946518) in prostate cancer occurrence and progress in order to provide data for screening high-risk Han Chinese individuals.

\section{MATERIAL AND METHODS}

\section{Study subjects}

From 2006 to 2010, this study recruited 375 prostate cancer patients from the inpatient department of West China Hospital and Sichuan Provincial People's Hospital in Chengdu, China, together with 400 age-matched controls. Pathological biopsy served as supporting evidence in the prostate cancer diagnosis. The histopathological type of all patients recruited was adenocarcinoma. Two urologists independently evaluated clinical stage according to the combination of Gleason Scores and TNM (tumor, node, metastasis) stage. Patients with any immune disease or other tumors were excluded from this study. A subset of 181 patients who had been receiving androgen deprivation therapy, including operational and medical castration, were followed up regularly to assess the potential effect of $I L-18$ gene promoter polymorphisms on the progress of prostate cancer. Glutamate pyruvate transaminase, blood urea nitrogen, prostate-specific antigen (PSA), serum testosterone, and blood routine examinations were performed for each patient receiving endocrine therapy at stated intervals to evaluate the therapeutic effect and disease progress. The clinical data of each patient were collected by telephone calls or a face-to-face interview in the outpatient clinic. Progress of prostate cancer was defined as two consecutive rises of total PSA (tPSA) at an interval of at least 2 weeks with the castrated serum testosterone level or new focus in imaging findings. Progression-free survival time was described as the specific period from the beginning of therapy to the progress date. Follow-up was carried out until December 2011. Due to the loss of follow-up and insufficient follow time, 34 patients were excluded from the final analysis. The mean and median follow times were $31.22 \pm 12.74$ and 30.00 months, respectively. Through health examinations, we identified 400 age-matched men who had no personal or family cancer history with a tPSA level of $<2 \mathrm{ng} / \mathrm{mL}$ as controls. All blood samples were stored at $-80^{\circ} \mathrm{C}$. The participants agreed to the use of their blood samples and clinical information for scientific research.

\section{SNP genotyping}

After DNA extraction, samples were randomly placed on 96-well plates and were analyzed using real-time PCR. The PCR primer designs, reaction mixture composition, and reaction processes of this study were the same as that used in a previous study (Liu et al., 2011). Standard samples were sequenced by a BigDye Terminator v3.1 Cycle Sequencing Kit (Applied Biosystems, USA) and ABI 3130 genetic analyzer (Applied Biosystems). Genotyp- 
ing results of all samples were obtained from the Gene Scanning v1.2 software by comparison with standard samples.

\section{Statistical analysis}

The observed genotype frequencies in the controls were tested for Hardy-Weinberg equilibrium (HWE). Possible significant difference in age was tested by the Student $t$-test. The distribution of genotypes and allele frequencies between the two groups was analyzed by the chi-square analysis. Haplotype analysis was carried out with a related software platform (Shi and $\mathrm{He}, 2005$; $\mathrm{Li}$ et al., 2009). Odds ratio and 95\% confidence interval $(95 \% \mathrm{CI})$ calculations were conducted with the risk option of Crosstabs. Kaplan-Meier and multivariate Cox proportional hazard models were used to examine the relationship of the genotypes and progressionfree survival time. Hazard ratios (HR) and 95\%CI were calculated. A two-side of $\mathrm{P}<0.05$ was considered to be statistically significant.

\section{RESULTS}

\section{Subject characteristics}

The genotype distribution of the controls was in HWE ( $\mathrm{P}>0.05$ for both polymorphisms). The mean ages for cases and controls were $71.24 \pm 9.88$ and $70.13 \pm 9.80$ years, respectively $(\mathrm{P}=0.118$, Table 1$)$. Based on the clinical findings, 113 patients were in clinical stage I or II, and 262 patients were in clinical stage III or IV (Table 1).

Table 1. Basic clinical data of patients.
\begin{tabular}{lcccc}
\hline Variables & Subgroups & Cases $(\mathrm{N}=375)(\%)$ & Controls $(\mathrm{N}=400)$ & P \\
\hline Age $[($ years $) \pm \mathrm{SD}]$ & & $71.24 \pm 9.88$ & $70.13 \pm 9.80$ & 0.118 \\
Clinical stages & I & $29(7.73)$ & & \\
& II & $84(22.40)$ & & \\
& III & $114(30.40)$ & & \\
& IV & $148(39.47)$ & & \\
\hline
\end{tabular}

\section{No association between SNPs and susceptibility of prostate cancer}

The association analyses of allele and genotype with prostate cancer susceptibility are shown in Table 2. No difference was observed between the genotype distribution of the two SNPs in the cases and controls $(\mathrm{P}=0.191$ and 0.499 for $-137 \mathrm{G} / \mathrm{C}, \mathrm{P}=0.278$ and 0.520 for $-607 \mathrm{C} / \mathrm{A})$. No significant association was detected in the allele frequencies either $(\mathrm{P}=0.135$ for $-137 \mathrm{G} / \mathrm{C}, \mathrm{P}=0.529$ for $-607 \mathrm{C} / \mathrm{A})$. On the basis of the haplotype analysis in Table 3, no promising $\mathrm{P}$ value was detected $(\mathrm{P}>0.05$ for all).

\section{Association between cancer progression and genotypes}

In this study, disease progress was represented by progression-free survival time. The 
mean and median progression-free survival times in this study were $20.68 \pm 13.77$ and 18 months, respectively. The distinction of cancer progress among different genotypes in the two SNPs is described in Table 4. Carriers of the GG genotype in $-137 \mathrm{G} / \mathrm{C}$ had a 2.165 -times higher risk of progress compared with that of $\mathrm{GC}$ carriers $(\mathrm{HR}=2.165,95 \% \mathrm{CI}=1.270-3.687)$ (Figure 1). No significant difference was found in the progress among three genotypes of the $-607 \mathrm{C} / \mathrm{A}$ polymorphism. Taking into account two subject characteristics, age at diagnosis and clinical stage, further investigation of the $-137 \mathrm{G} / \mathrm{C}$ genotypes showed that clinical stage III and IV patients with the GG genotype had worse progression-free survival than GC carriers $(\mathrm{HR}=2.174,95 \% \mathrm{CI}=1.211-3.906)($ Table 5; Figure 2). No significant effect was detected for age (Table 5).

Table 2. Genotypes and allele frequencies of IL-18 promoters in relation to the occurrence of prostate cancer.

\begin{tabular}{|c|c|c|c|c|c|c|}
\hline Polymorphisms & Cases $(\mathrm{N}=375)(\%)$ & Controls $(\mathrm{N}=400)(\%)$ & $\chi^{2}$ & $\mathrm{P}$ & OR & $95 \% \mathrm{CI}$ \\
\hline \multicolumn{7}{|l|}{ IL-18 -137G/C } \\
\hline \multicolumn{7}{|l|}{ Genotypes } \\
\hline GG (605) & $301(80.27)$ & $304(76.00)$ & & & 1.00 & \\
\hline $\mathrm{GC}(168)$ & $74(19.73)$ & $94(23.50)$ & 1.71 & 0.19 & 0.80 & $0.56-1.12$ \\
\hline $\mathrm{CC}(2)$ & $0(0.00)$ & $2(0.50)$ & - & 0.50 & - & - \\
\hline \multicolumn{7}{|l|}{ Alleles } \\
\hline G (1378) & $676(90.13)$ & $702(87.75)$ & & & 1.00 & \\
\hline$C(172)$ & $74(9.87)$ & $98(12.25)$ & 2.23 & 0.14 & 0.78 & $0.57-1.08$ \\
\hline IL-18 -607C/A & & & & & & \\
\hline \multicolumn{7}{|l|}{ Genotypes } \\
\hline CC (194) & $100(26.67)$ & $94(23.50)$ & & & 1.00 & \\
\hline $\mathrm{CA}(368)$ & $172(45.87)$ & $196(49.00)$ & 1.18 & 0.28 & 0.83 & $0.58-1.17$ \\
\hline AA (213) & $103(27.47)$ & $110(27.50)$ & 0.41 & 0.52 & 0.88 & $0.60-1.30$ \\
\hline \multicolumn{7}{|l|}{ Alleles } \\
\hline C (756) & $372(49.60)$ & $384(48.00)$ & & & 1.00 & \\
\hline A (794) & $378(50.40)$ & $416(52.00)$ & 0.40 & 0.53 & 0.94 & $0.77-1.15$ \\
\hline
\end{tabular}

$\mathrm{OR}=$ odds ratio $; 95 \% \mathrm{CI}=95 \%$ confidence interval.

Table 3. Haplotype frequencies of IL-18 promoters in prostate cancer patients and controls.

\begin{tabular}{lcccc}
\hline Haplotypes & Cases $(2 \mathrm{n}=750)(\%)$ & Controls $(2 \mathrm{n}=800)(\%)$ & OR & $95 \% \mathrm{CI}$ \\
\hline$-607 \mathrm{C} /-137 \mathrm{G}$ & $360(48.00)$ & $373(46.60)$ & 1.000 & - \\
$-607 \mathrm{C} /-137 \mathrm{C}$ & $12(1.60)$ & $11(1.40)$ & 1.130 & $0.492-2.594$ \\
$-607 \mathrm{~A} /-137 \mathrm{G}$ & $316(42.20)$ & $329(41.10)$ & 0.995 & $0.805-1.230$ \\
$-607 \mathrm{~A} /-137 \mathrm{C}$ & $62(8.2)$ & $87(10.90)$ & 0.738 & $0.517-1.055$ \\
\hline
\end{tabular}

$\mathrm{OR}=$ odds ratio $; 95 \% \mathrm{CI}=95 \%$ confidence interval.

Table 4. Survival analysis of the selected SNPs in patients $(N=147)$.

\begin{tabular}{|c|c|c|c|c|c|}
\hline Polymorphisms & Genotypes & $\mathrm{N}($ all, $\mathrm{N}=147)(\%)$ & $\mathrm{N}($ developed, $\mathrm{N}=99)(\%)$ & HR & $95 \% \mathrm{CI}$ \\
\hline \multirow[t]{3}{*}{ IL-18 -607C/A } & GG & $37(25.17)$ & $26(70.27)$ & 1.000 & \\
\hline & $\mathrm{TT}$ & $105(71.43)$ & $72(68.57)$ & 1.045 & $0.664-1.643$ \\
\hline & GT & $5(3.40)$ & $1(20)$ & 0.220 & $0.030-1.643$ \\
\hline \multirow[t]{2}{*}{ IL-18 -137G/C } & GC & $31(21.09)$ & $17(54.84)$ & 1.000 & \\
\hline & GG & $116(78.91)$ & $82(70.69)$ & 2.165 & $1.270-3.687$ \\
\hline
\end{tabular}

$\mathrm{HR}=$ hazard ratio $; 95 \% \mathrm{CI}=95 \%$ confidence interval. 


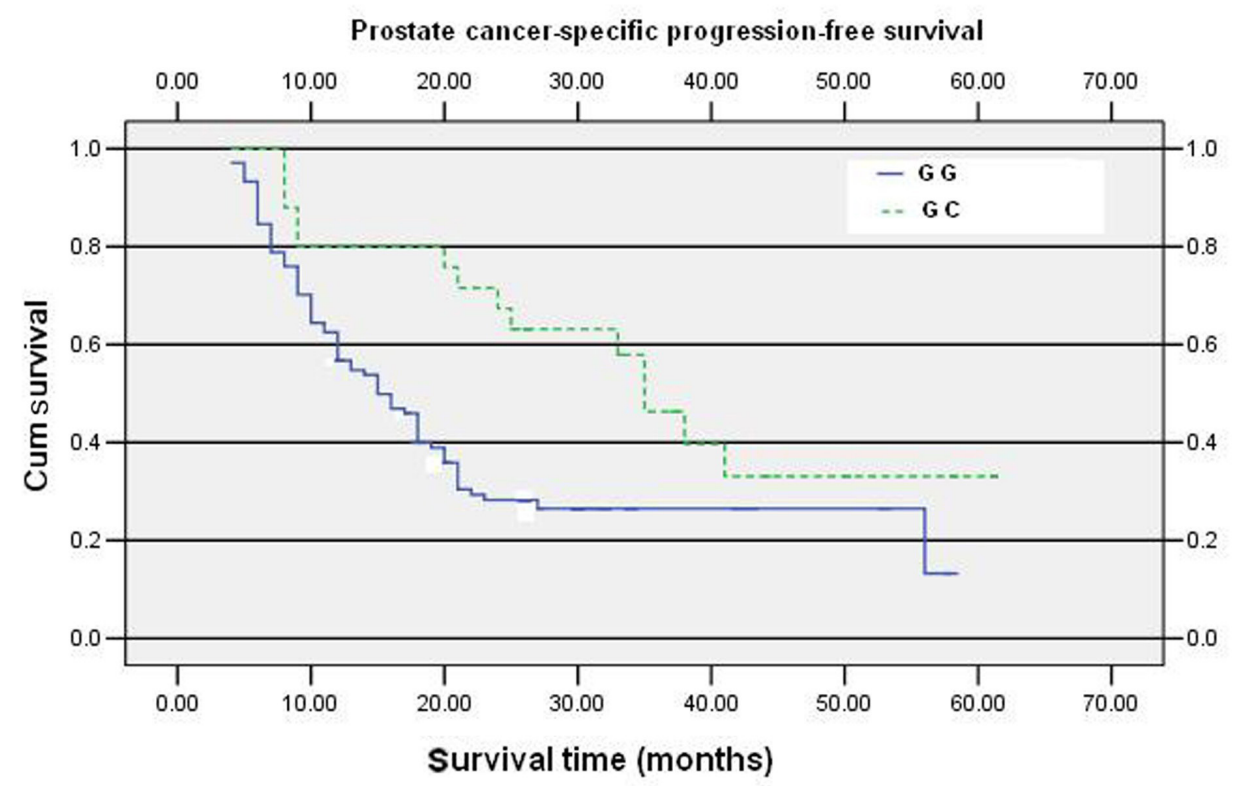

Figure 1. Progression-free survival time of the prostate cancer patients carrying GG or GC genotypes of the SNP $-137 \mathrm{G} / \mathrm{C}$. Cum $=$ cumulative.

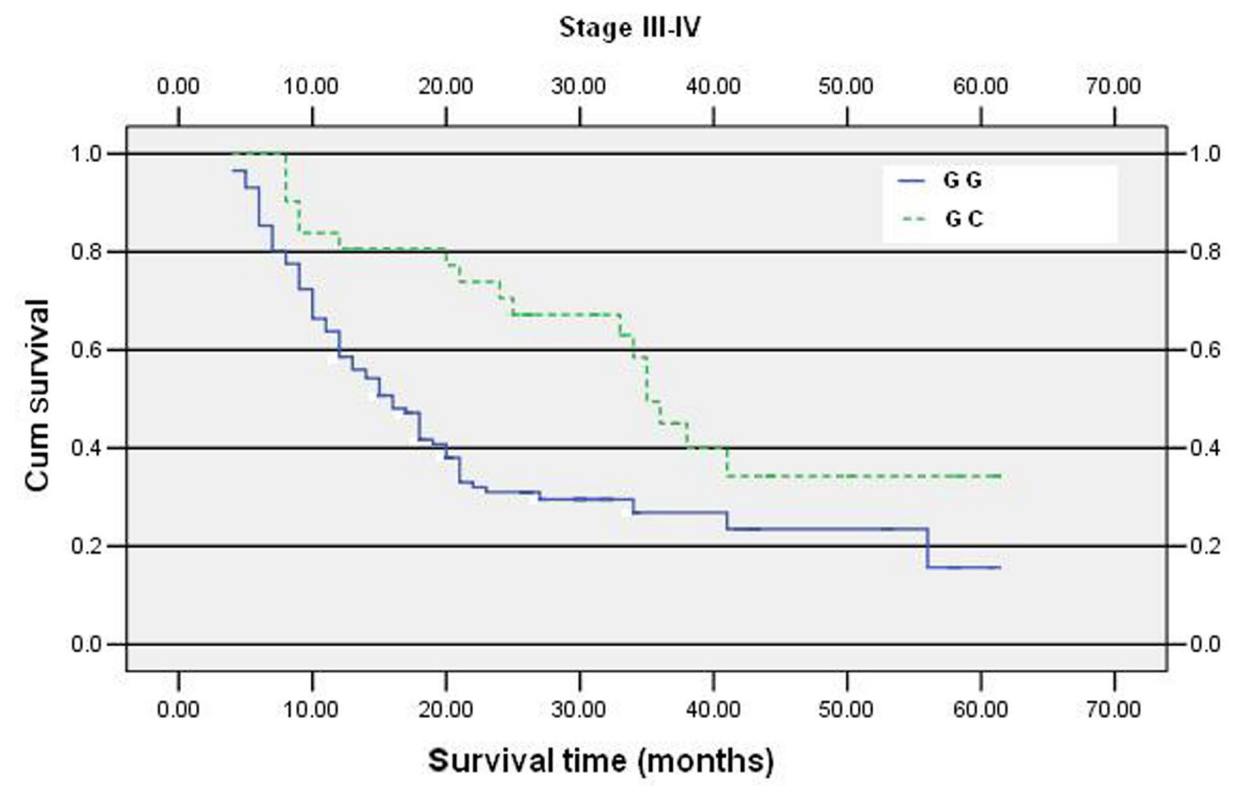

Figure 2. Progression-free survival time of the prostate cancer patients in clinical stages III and IV at the diagnosis carrying GG or GC genotypes of the SNP $-137 \mathrm{G} / \mathrm{C}$. Cum = cumulative. 


\begin{tabular}{|c|c|c|c|c|c|}
\hline Characteristics & Genotypes of IL-18 -137G/C & $\mathrm{N}($ all, $\mathrm{N}=147)(\%)$ & $\mathrm{N}$ (developed, $\mathrm{N}=99)(\%)$ & $\mathrm{HR}$ & $95 \% \mathrm{CI}$ \\
\hline Age (years) & GC & $11(7.48)$ & $4(36.36)$ & 1.000 & \\
\hline$\leq 65$ & GG & $24(16.33)$ & $16(66.67)$ & 2.821 & $0.923-8.619$ \\
\hline \multirow[t]{3}{*}{$>65$} & $\mathrm{GC}$ & $20(13.61)$ & $13(65.00)$ & 1.000 & \\
\hline & GG & $92(62.59)$ & $66(71.74)$ & 1.711 & $0.936-3.127$ \\
\hline & $\mathrm{GC}$ & $6(4.08)$ & $3(50)$ & 1.000 & \\
\hline Clinical stage & GG & $12(8.16)$ & $7(58.33)$ & 1.541 & $0.392-6.061$ \\
\hline I, II & $\mathrm{GC}$ & $25(17.01)$ & $14(56.00)$ & 1.000 & \\
\hline III, IV & GG & $104(70.75)$ & $75(72.12)$ & 2.174 & $1.211-3.906$ \\
\hline
\end{tabular}

\section{DISCUSSION}

Prostate cancer is the most common disease in males, and features such high heterogeneity that its pathogenesis and progression vary widely in different patients. It is believed that genetic variants are the main risk factors that contribute to prostate cancer. There is now substantial knowledge that many genes and chromosome segments are significantly associated with prostate cancer risks in a multiethnic population, such as PCA3 (Zhou et al., 2011), CYP17 (Wang et al., 2011), TP53 (Stacey et al., 2011), 8q24 (Zeegers et al., 2011), and 9q22 (Wentzensen et al., 2011). However, no comprehensive knowledge on the precise mechanism of the interaction of these genetic factors, especially in the prognosis of prostate cancer, has been provided to date. Prostate cancer risk and prognosis after androgen deprivation therapy were investigated in this study. The $-137 \mathrm{G} / \mathrm{C}$ GG genotype was associated with poor prognosis, indicating the value of $I L-18-137 \mathrm{G} / \mathrm{C}$ polymorphism as a potential prognostic marker in prostate cancer patients undergoing androgen deprivation therapy.

The $I L-18$ promoter region is composed of five single nucleotide polymorphic positions, in which only $-137 \mathrm{G} / \mathrm{C}$ (rs 187238) and -607C/A (rs1946518) have confirmed impact on IL-18 activity and expression in tissues (Kalina et al., 2000; Giedraitis et al., 2001). Other than this, different haplotypes of $I L-18$ polymorphisms might lead to different expression levels of $I L-18$ mRNA (Giedraitis et al., 2001). For example, -137G/-607C has a higher level of $I L-18$ mRNA synthesis (Giedraitis et al., 2001), while the haplotype (-137C/-607A) has a lower promoter activity (Takagawa et al., 2005). However, in this study, no significant associations with the susceptibility of prostate cancer were detected in these two SNPs, indicating that differential expression of $I L-18$ may not contribute to the occurrence of this tumor. These data disagreed with those of a previously published study on the Chinese population reporting that the $-137 \mathrm{G} / \mathrm{C}$ polymorphism and the $-137 \mathrm{C} /-607 \mathrm{~A}$ haplotype were associated with a significantly higher risk for prostate cancer (Liu et al., 2007). Thus, the pathogenesis mechanisms in the two promoter polymorphisms and prostate cancer in the Chinese population in general are not completely clear. Further evaluation of a large sample is needed to confirm the underlying relationship.

Androgen deprivation therapy has wide application in prostate cancer therapy, especially in patients in advanced stage and in remission after radical operation. It has been reported that androgen deprivation therapy could retard, suppress, or prevent the carcinogenic progression of prostate cancer in the hormone-dependent growth pattern of most cancer cells. The average progression-free survival time observed in clinical practice is 12-33 months during endocrine therapy (Figg et al., 2004). However, owing to the high heterogeneity and mul- 
tifocal growth of prostate cancer, the response to endocrine therapy among different patients varies widely. Thus, identification of a prognostic molecular marker might influence the therapeutic effect as well as the alternative of modality in the treatment. In this study, the $-137 \mathrm{G} / \mathrm{C}$ polymorphism GG genotype was associated with a shorter progression-free survival time. G at position -137 had a higher expression level of $I L-18$ mRNA, indicating that IL-18 might act as a pro-tumor factor in the progress of tumors. Some previous findings have supported and partly explained the observed poor survival of carriers of the variant allele in this study. The IL-18 protein has been shown to be overexpressed in common skin tumors (Charles, 1999; Park et al., 2001). Three more case-control studies about the progression of gastric cancer and breast cancer (Merendino et al., 2001; Eissa et al., 2005; Ye et al., 2007) detected a higher IL18 level in the tumor region and in the serum with metastasis. Similarly, prostate cancer cells could produce IL-18, which could be equally predictive as a pathologic stage on multivariate analysis (log rank test, $\mathrm{P}=0.02$ ) (Lebel-Binay et al., 2003). Furthermore, Bushley et al. (2004) and Pratesi et al. (2006) reported that there was linkage between $-137 \mathrm{G} / \mathrm{C}$ and $-607 \mathrm{C} / \mathrm{A}$ polymorphisms of $I L-18$ and the progression of ovarian cancer and nasopharyngeal carcinoma. Taken together, the $I L-18-137 \mathrm{G} / \mathrm{C}$ polymorphism could be used as an independent prognostic marker in prostate cancer androgen deprivation therapy.

In summary, our data demonstrated that the $I L-18-137 \mathrm{G} / \mathrm{C}$ promoter polymorphism might contribute to the prognosis of prostate cancer patients after androgen deprivation therapy. Our results did not indicate any significant association between the two polymorphisms and the occurrence of prostate cancer, which does not imply exclusion of the contribution to the risk of prostate cancer from other polymorphisms in $I L$ - 18 . Additional prospective studies with large samples, detailed clinical data, and long-term follow-up are needed to confirm our results in the future.

\section{ACKNOWLEDGMENTS}

Research supported by grants from the National Natural Science Foundation of China (\#81101939).

\section{REFERENCES}

Alexandrakis MG, Passam FH, Sfiridaki K, Moschandrea J, et al. (2004). Interleukin-18 in multiple myeloma patients: serum levels in relation to response to treatment and survival. Leuk. Res. 28: 259-266.

Amin MA, Mansfield PJ, Pakozdi A, Campbell PL, et al. (2007). Interleukin-18 induces angiogenic factors in rheumatoid arthritis synovial tissue fibroblasts via distinct signaling pathways. Arthritis Rheum. 56: 1787-1797.

Bushley AW, Ferrell R, McDuffie K, Terada KY, et al. (2004). Polymorphisms of interleukin (IL)-1alpha, IL-1beta, IL-6, IL-10, and IL-18 and the risk of ovarian cancer. Gynecol. Oncol. 95: 672-679.

Charles AD (1999). Interleukin-18. Methods 19: 121-132.

Cho ML, Jung YO, Moon YM, Min SY, et al. (2006). Interleukin-18 induces the production of vascular endothelial growth factor (VEGF) in rheumatoid arthritis synovial fibroblasts via AP-1-dependent pathways. Immunol. Lett. 103: 159-166.

Desai KV, Michalowska AM, Kondaiah P, Ward JM, et al. (2004). Gene expression profiling identifies a unique androgenmediated inflammatory/immune signature and a PTEN (phosphatase and tensin homolog deleted on chromosome 10)-mediated apoptotic response specific to the rat ventral prostate. Mol. Endocrinol. 18: 2895-2907.

Dinarello CA (1999). IL-18: A TH1-inducing, proinflammatory cytokine and new member of the IL-1 family. J. Allergy Clin. Immunol. 103: 11-24.

Eissa SA, Zaki SA, El-Maghraby SM and Kadry DY (2005). Importance of serum IL-18 and RANTES as markers for breast carcinoma progression. J. Egypt. Natl. Canc. Inst. 17: 51-55. 
Figg WD, Franks ME, Venzon D, Duray P, et al. (2004). Gleason score and pretreatment prostate-specific antigen in survival among patients with stage D2 prostate cancer. World J. Urol. 22: 425-430.

Fujita K, Ewing CM, Sokoll LJ, Elliott DJ, et al. (2008). Cytokine profiling of prostatic fluid from cancerous prostate glands identifies cytokines associated with extent of tumor and inflammation. Prostate 68: 872-882.

Fujita K, Ewing CM, Isaacs WB and Pavlovich CP (2011). Immunomodulatory IL-18 binding protein is produced by prostate cancer cells and its levels in urine and serum correlate with tumor status. Int. J. Cancer 129: 424-432.

Giedraitis V, He B, Huang WX and Hillert J (2001). Cloning and mutation analysis of the human IL-18 promoter: a possible role of polymorphisms in expression regulation. J. Neuroimmunol. 112: 146-152.

Gillies SD, Young D, Lo KM and Roberts S (1993). Biological activity and in vivo clearance of antitumor antibody/ cytokine fusion proteins. Bioconjug. Chem. 4: 230-235.

Han MY, Zheng S, Yu JM, Peng JP, et al. (2004). Study on interleukin-18 gene transfer into human breast cancer cells to prevent tumorigenicity. J. Zhejiang Univ. Sci. 5: 472-476.

Jung MK, Song HK, Kim KE, Hur DY, et al. (2006). IL-18 enhances the migration ability of murine melanoma cells through the generation of ROI and the MAPK pathway. Immunol. Lett. 107: 125-130.

Kalina U, Ballas K, Koyama N, Kauschat D, et al. (2000). Genomic organization and regulation of the human interleukin-18 gene. Scand. J. Immunol. 52: 525-530.

Kim KE, Song H, Kim TS, Yoon D, et al. (2007). Interleukin-18 is a critical factor for vascular endothelial growth factorenhanced migration in human gastric cancer cell lines. Oncogene 26: 1468-1476.

Lebel-Binay S, Thiounn N, De PG, Vieillefond A, et al. (2003). IL-18 is produced by prostate cancer cells and secreted in response to interferons. Int. J. Cancer 106: 827-835.

Li Z, Zhang Z, He Z, Tang W, et al. (2009). A partition-ligation-combination-subdivision EM algorithm for haplotype inference with multiallelic markers: update of the SHEsis (http://analysis.bio-x.cn). Cell Res. 19: 519-523.

Liu J, Liu J, Zhou Y, Li S, et al. (2011). Association between promoter variants of interleukin-18 and schizophrenia in a Han Chinese population. DNA Cell Biol. 30: 913-917.

Liu Y, Lin N, Huang L, Xu Q, et al. (2007). Genetic polymorphisms of the interleukin-18 gene and risk of prostate cancer. DNA Cell Biol. 26: 613-618.

Marshall DJ, Rudnick KA, McCarthy SG, Mateo LR, et al. (2006). Interleukin-18 enhances Th1 immunity and tumor protection of a DNA vaccine. Vaccine 24: 244-253.

Merendino RA, Gangemi S, Ruello A, Bene A, et al. (2001). Serum levels of interleukin-18 and sICAM-1 in patients affected by breast cancer: preliminary considerations. Int. J. Biol. Markers 16: 126-129.

Okamura H, Tsutsi H, Komatsu T, Yutsudo M, et al. (1995). Cloning of a new cytokine that induces IFN-gamma production by T cells. Nature 378: 88-91.

Park H, Byun D, Kim TS, Kim YI, et al. (2001). Enhanced IL-18 expression in common skin tumors. Immunol. Lett. 79: 215-219.

Pratesi C, Bortolin MT, Bidoli E, Tedeschi R, et al. (2006). Interleukin-10 and interleukin-18 promoter polymorphisms in an Italian cohort of patients with undifferentiated carcinoma of nasopharyngeal type. Cancer Immunol. Immunother. 55: 23-30.

Shi YY and He L (2005). SHEsis, a powerful software platform for analyses of linkage disequilibrium, haplotype construction, and genetic association at polymorphism loci. Cell Res. 15: 97-98.

Stacey SN, Sulem P, Jonasdottir A, Masson G, et al. (2011). A germline variant in the TP53 polyadenylation signal confers cancer susceptibility. Nat. Genet. 43: 1098-1103.

Takagawa T, Tamura K, Takeda N, Tomita T, et al. (2005). Association between IL-18 gene promoter polymorphisms and inflammatory bowel disease in a Japanese population. Inflamm. Bowel. Dis. 11: 1038-1043.

Tse BW, Russell PJ, Lochner M, Förster I, et al. (2011). IL-18 inhibits growth of murine orthotopic prostate carcinomas via both adaptive and innate immune mechanisms. PLoS One 6: e24241.

Wang F, Zou YF, Feng XL, Su H, et al. (2011). CYP17 gene polymorphisms and prostate cancer risk: a meta-analysis based on 38 independent studies. Prostate 71: 1167-1177.

Wentzensen N, Black A, Jacobs K, Yang HP, et al. (2011). Genetic variation on 9p22 is associated with abnormal ovarian ultrasound results in the prostate, lung, colorectal, and ovarian cancer screening trial. PLoS One 6: e21731.

Xia D, Li F and Xiang J (2004). Engineered fusion hybrid vaccine of IL-18 gene-modified tumor cells and dendritic cells induces enhanced antitumor immunity. Cancer Biother. Radiopharm. 19: 322-330.

Ye ZB, Ma T, Li H, Jin XL, et al. (2007). Expression and significance of intratumoral interleukin-12 and interleukin-18 in human gastric carcinoma. World J. Gastroenterol. 13: 1747-1751.

Yoon- DY, Cho YS, Park JW, Kim SH, et al. (2004). Up-regulation of reactive oxygen species (ROS) and resistance to Fas-mediated apoptosis in the C33A cervical cancer cell line transfected with IL-18 receptor. Clin. Chem. Lab. Med. 42: 499-506. 
Zeegers MP, Khan HS, Schouten LJ, van Dijk BA, et al. (2011). Genetic marker polymorphisms on chromosome 8q24 and prostate cancer in the Dutch population: DG8S737 may not be the causative variant. Eur. J. Hum. Genet. 19: 118-120.

Zhou W, Chen Z, Hu W, Shen M, et al. (2011). Association of short tandem repeat polymorphism in the promoter of prostate cancer antigen 3 gene with the risk of prostate cancer. PLoS One 6: e20378. 